\title{
Special Issue: Green Management for Sustainable Sugar Industry
}

\author{
S. Solomon ${ }^{1}$ Robert Graham Quirk ${ }^{2}$ S. K. Shukla ${ }^{3}$
}

Published online: 31 January 2019

(C) Society for Sugar Research \& Promotion 2019

Sugarcane has been cultivated for human and animal consumption for centuries, and in recent years, its potential is being increasingly exploited for its immense agro-industrial value. World sugarcane production has more than 500 years of history and integrates the agricultural activities of growing, harvesting and transportation of sugarcane with industrial production in sugar mills and integrated industries viz. ethanol, power, feed, paper, board and biobased products. Sugar industry and sugar crops are a potential source of renewable energy, bio-fuels, bio-electricity and bio-materials, as well as a food crop and widely recognized as a source of rural livelihoods and socio-economic transformation in developing countries. Like many other industries, the sugar and sugar-bioproduct industries are facing important sustainability issues and opportunities. The relatively low and fluctuating profit from sugar, surpluses of sugar, world-wide trend to produce alternative from renewable raw material, reduce greenhouse gases, water- and energy-intensive factories and refineries, and increased consumer demands for sustainably manufactured products are putting pressure on the industries to diversify

S. Solomon

presidentssrp@gmail.com

Robert Graham Quirk

rgquirk@bigpond.com

S. K. Shukla

sudhirshukla151@gmail.com

1 CSA University of Agriculture and Technology, Kanpur, Uttar Pradesh, India

230 Duranbah Road, Duranbah, NSW 2487, Australia

3 AICRP(S), ICAR-Indian Institute of Sugarcane Research, Lucknow, Uttar Pradesh 226002, India

for sustainability. The progressive transition from conventional sugar mill and distilleries to bio-refineries, coupled with climate change, has led to multiple problems encompassing crop vulnerability to biotic and abiotic stress, high cost of production as well as its adverse impact on environment, which are serious concerns. World over, systematic efforts are underway to determine critical issues that threaten the environmental and economic sustainability of sugar industry and green management intervention to improve their profitability and productivity vis-a-vis a reduction in the cost of production.

This special issue of Sugar Tech is a unique collection of a total of 21 review articles and research papers based on the views and experience of many experts, highlighting the existing knowledge of Green Technologies and its benefits for sustainable sugarcane production and industry. Besides, it will also include articles on the use of sugarcane as raw material in bio-refineries to produce sugar and biomassbased value-added products and derivatives in cleaner environment.

Other important contributions in this special issue cover ecological concerns related to sugarcane/sugar crops production and processing, bio-intensive sugarcane agriculture, carbon sequestration, water and energy footprints, corporate social responsibility (CSR), bio-based products from sugar crops, green business initiatives and sustainability issues. 


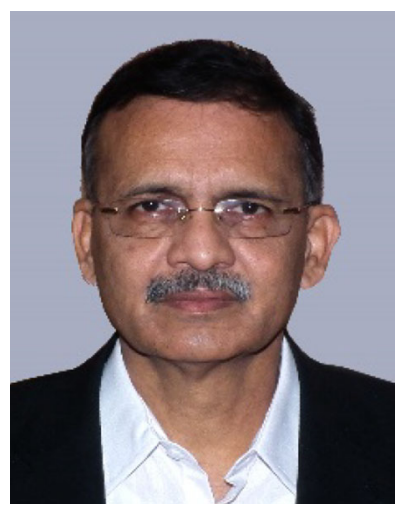

\section{Dr. S. Solomon}

Dr. S. Solomon received his Doctorate degree from Punjab Agricultural University, Ludhiana (India) and joined Agricultural Research Service of Indian Council of Agricultural Research (ICAR-Ministry of Agriculture) in 1977. As a Director of the Indian Institute of Sugarcane Research, Lucknow, he was actively involved in the development and transfer of relevant technologies to the sugarcane farmers and industry for their sustainable development. During his 36 years of research career, he has published over 120 research papers, 22 books and many technical reports for the benefit of global sugar industry. He has done pioneering work on sugarcane quality and post-harvest management of sugarcane. Dr. Solomon is the President of Society for Sugar Research and Promotion and Vice-President of the International Association of Professionals in Sugar and Integrated Industries (IAPSIT) and on the advisory bodies of many national and international organizations. As an advisor he has visited Brazil, Australia, China, Vietnam, Egypt, Iran, Sri Lanka, Cuba, Thailand, etc. He is also the Editor-in-Chief of an international journal-Sugar Tech, published by Springer, and also organized many international sugar conferences.

The Government of China bestowed on him the most prestigious honour-Friendship Award in 2005 in view of his active role in promoting collaboration and partnership amongst sugar producing countries. Besides, he is a recipient of many international honours and awards viz., JinXiu Qui Award, P.R. China (2005), Award of Excellence-IAPSIT(2006), Sinai University Peace Award-Al Arish University, Egypt (2008), Global Award of Excellence-IAPSIT (2008), Indira Gandhi Award (2013), Lifetime Achievement Award-IAPSIT(2014), Lifetime Achievement Award-UPAAS (2014), Hari Om Ashram Trust Award-ICAR(2012-13), Dr. Rajendra Prasad Award-ICAR and Noel Deerr Gold Medal-STAI (2014, 2016) and Leadership Excellence Award (2018) from Thailand Society of Sugarcane and Sugar Technologists. $\mathrm{He}$ represented the Indian scientists delegation at
International Society of Sugarcane Technologists Conference at Chiang Mai in 2016 and also at Udon Thani (Thailand) in 2018. He is a member of many national and international societies and on the Board of leading agricultural universities and research institutions in the country.

Dr. Solomon is currently working as Vice Chancellor of Chandra Shekhar Azad University of Agriculture and Technology, Kanpur, since December, 2016, a premier Agricultural University in North India. As a CEO and VC of the university, he is managing and mentoring a team of over 2300 students and 250 teachers engaged in agricultural education, research and extension.

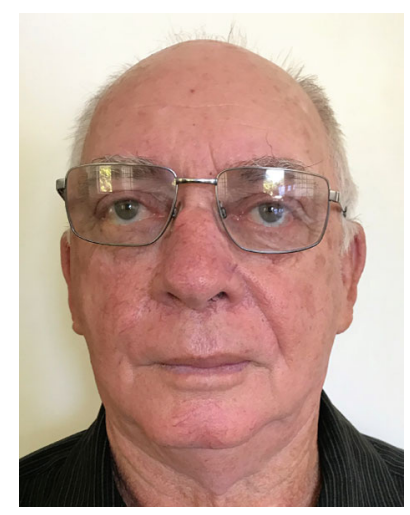

Mr. Robert Graham Quirk, 30 Duranbah Road Duranbah NSW 2487, Australia

Mr. Quirk has vast experience in sugarcane research in collaboration with four Australian Universities for the past 18 years. Mr Quirk has developed Best Management Practice (BMP) for sugar cane growing in coastal acid sulphate soils. Now, these practices have been accepted as BMP for the 2 million + hectares of this landscape globally. He has authored and co-authored scientific sustainable agriculture papers for international conferences and Congresses in 18 countries. He is a member of the prestigious International Union of Soil Sciences working group for acid sulphate soils and has been invited to be the keynote speaker at their congress in 2012. He was awarded a Churchill Fellowship in 2001 to study acid sulphate soil remediation in the USA, the Netherlands and China. He was awarded the Presidents Medal by the Australian Society of Sugar Cane Technologists for the most useful research to the Australian sugar industry in 2001. He was awarded the prestigious 16th McKell medal for Australia in 2005, awarded each year by the Ministerial Council of Australia for excellence and achievement in Natural Resource Management. He is one of the top 50 most influential Australians for the environment. He is recognized by that same list as one of the top 100 sustainability 
leaders in the world (as recognized by the ABC carbon top 50 list). He was awarded a lifetime achievement award in 2018 by the Society for Sugar Research and Promotion. He has delivered several invited lectures and seminars at some of the most prestigious Universities and international conferences around the world. He has been a member of Editorial board of Sugar Tech, an international journal of sugar crops and related industries.

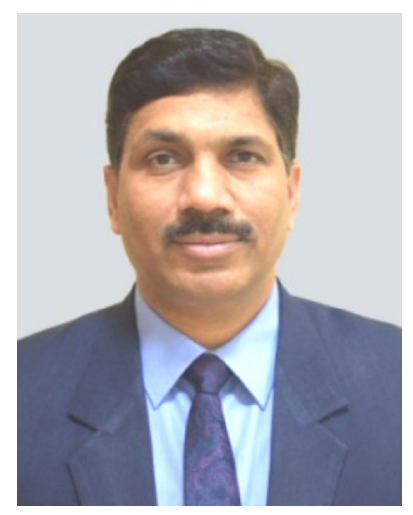

\section{Dr. Sudhir Kumar Shukla}

Dr. S K started his career as scientist in 1993, passed Agricultural Research Services (ARS) in 1991 and served at Indian Institute of Sugarcane Research, Lucknow, for more than 24 years. He has made outstanding contributions in the field of Sugarcane-Based Cropping System Research. His major research work is focused on improving carbon sequestration in sugarcane-based system in changing climatic scenario, role of bio agents, viz. Trichoderma and Gluconacetobacter, in modulating rhizospheric environment and improving crop productivity, optimizing soil moisture regime, deep tillage in plant-ratoon system and its effect on soil carbon, water, nutrient use efficiencies and crop yield. His pioneering contribution on sugarcane trash management and improving sprouting of winter-initiated ratoon through $\mathrm{K}$ fertilization and conservation agriculture has ample scope for improving crop productivity vis-à-vis reducing cost of production and sustaining soil health in Uttar Pradesh.

He has published more than 60 research papers, 5 books, 12 book chapters, 10 technical bulletins and 20 reports. Dr Shukla guided and trained 17 students of B.Tech., M.Sc., M.Phil. and Ph.D. He is a recipient of Noel Deerr Gold Medal for outstanding contributions in carbon sequestration in sugarcane-based system, Pt. Ram Ratan Smrati Samman for outstanding work in field of agriculture and $\mathrm{M}$. S. Swaminathan Award for outstanding work in Sugarcane Agriculture, recipient of Indian Society of Agronomy (ISA) Fellow-2014, FAI Award for outstanding work on integrated nutrient management in sugarcane in 2014. He was also awarded UPAAS Fellow-2014 in the field of Natural Resource Management from Uttar Pradesh Academy of Agricultural Sciences (UPAAS) and Society of Agricultural Professionals (SAP) Gold medal-2015 for outstanding work in Natural Resource Management. He received Outstanding Scientist award-2015 from International Society of Plant Sciences, Agriculture and Horticulture Sciences. He has presented over 60 papers in national and international forum.

Publisher's Note Springer Nature remains neutral with regard to jurisdictional claims in published maps and institutional affiliations. 